\title{
Detection of a Proteinase Inhibitor in Aspergillus nidulans
}

\author{
By HASSAN ANSARI AND LEWIS STEVENS* \\ Department of Biochemistry, University of Stirling, Stirling FK9 4LA, U.K.
}

(Received 5 February 1982; revised 14 June 1982)

\begin{abstract}
The activity of proteinases in mycelial extracts of Aspergillus nidulans increased during storage. The rate of activation increased with temperature. Three separate proteinase activities, differing in their electrophoretic mobilities on polyacrylamide gels, were readily detected at pH 6.5. Inhibitory activity, effective against all three proteinase activities, was also detected in fractions prepared from fresh mycelial extracts. The inhibitory factor(s) were heat-stable and non-dialysable. The inhibitory activity was lost during storage of mycelial extracts. It is proposed that the inhibitory factor(s) are digested by the proteinases during storage.
\end{abstract}

\section{INTRODUCTION}

Mycelial extracts from Aspergillus nidulans have been shown to contain at least five different proteinase activities detectable at near-neutral $\mathrm{pH}$ values (Cohen, 1973). Of these activities one is exclusively intracellular, whereas the rest appear both in mycelial extracts and in culture filtrates. It has also been shown that the proteinase activity of a mycelial extract increases on storage and that this is accompanied by a change in the electrophoretic band pattern of the proteinase which is exclusively intracellular (Cohen, 1973). Similar increases in proteinase activity on storage have also been observed in extracts from Aspergillus niger (Stevens et al., 1981), Phycomyces blakesleeanus (Fischer \& Thomson, 1979) and in Saccharomyces cerevisiae (Meussdoerffer et al., 1980). In $S$. cerevisiae, where the most extensive investigations have been carried out, the proteinases $A$ and $B$ and carboxypeptidase $Y$ have been found to be inactive in freshly prepared crude extracts (Wolf \& Holzer, 1980). This inactivity is due to the presence of specific proteinase inhibitors, which in the intact organism occur in a separate compartment, but which in disrupted cell extracts are able to combine with the proteinases. These inhibitors become digested when crude extracts are allowed to autolyse. Similar inhibitors have been detected in Neurospora crassa (Yu et al., 1974) and in P. blakesleeanus (Fischer \& Thompson, 1979).

In this paper we investigate the mechanism of activation of intracellular proteinases from $A$. nidulans as an essential first step towards understanding their function in vivo during different nutritional or physiological states.

\section{METHODS}

Organism and growth conditions. Aspergillus nidulans BWB 272 was maintained on malt agar and grown in submerged culture as described previously (Stevens et al., 1976). Mycelia from cultures grown for $24 \mathrm{~h}$ at $37^{\circ} \mathrm{C}$ were harvested by filtration.

Preparation of mycelial extracts and proteinase assays. The mycelial pellets were ground in a mortar with half their weight of acid-washed sand and then mixed with approximately 5 vol. $10 \mathrm{mM}$-potassium phosphate $/ 0 \cdot 1 \mathrm{mM}$ EDTA $/ 0.01 \%(\mathrm{v} / \mathrm{v})$ Triton $\mathrm{X}-100, \mathrm{pH} 7 \cdot 2$. The suspension was centrifuged at $27000 \mathrm{~g}$ for $30 \mathrm{~min}$ and the supernatant (referred to as the 'crude extract') was used for enzyme assays. Proteinases from $A$. nidulans can be separated by PAGE into three bands, I, II and III (see Results). For some experiments one of these bands, peak I, was partially purified. For this purification the crude extract was fractionated by the following steps: (1) $\left(\mathrm{NH}_{4}\right)_{2} \mathrm{SO}_{4}$ fractionation, collecting the fraction precipitating between $40 \%$ and $90 \%$ saturation; (2) fractionation on a Sephacryl S-300 column and (3) separation of peak I from peaks II and III using DEAE-cellulose with a salt 
gradient from $0.1 \mathrm{M}-\mathrm{NaCl} / 0.01 \mathrm{M}$-sodium phosphate buffer to $0.3 \mathrm{M}-\mathrm{NaCl} / 0.01 \mathrm{M}$-sodium phosphate buffer, $\mathrm{pH} 7 \cdot 0$. Proteinase activity was measured using hide powder azure as substrate suspended in $0.05 \mathrm{M}$-Tris/maleate buffer, pH 6.5, in a final volume of $1.1 \mathrm{ml}$ (Cohen, 1973; Stevens et al., 1981). One unit of proteinase activity is defined as that which releases dye of $A_{595}$ value $1\left(1 \mathrm{~cm}\right.$ light path) $\mathrm{h}^{-1}$ at $45^{\circ} \mathrm{C}$. Protein estimations were carried out by measurement of the change in absorption spectra when proteins bind Coomassie brilliant blue G-250 (Sedmak \& Grossberg, 1977).

$P A G E$. This was performed using Tris/glycine buffer, $\mathrm{pH} 8 \cdot 3$, and incorporating azocasein into the gels as described previously (Ansari \& Stevens, 1981). The gels were incubated for $1 \mathrm{~h}$ at $45^{\circ} \mathrm{C}$ in $0.2 \mathrm{M}$-Tris/maleate buffer, $\mathrm{pH} 6.5$, then fixed in $6 \%(\mathrm{w} / \mathrm{v})$ TCA. They were suspended in $0.5 \mathrm{M}-\mathrm{NaOH}$ and scanned at $410 \mathrm{~nm}$ using a Gilford model 2410 linear transport system.

Inhibitors. A stock solution (100 $\mathrm{mM}$ ) of phenylmethane sulphonyl fluoride (PMSF) dissolved in dimethyl sulphoxide or a stock solution of $\mathrm{HgCl}_{2}(10 \mathrm{mM})$ was added to the crude mycelial extracts and incubated for $10 \mathrm{~min}$ at $20^{\circ} \mathrm{C}$ prior to either assaying for proteinase activity or application to the polyacrylamide gels.

\section{RESULTS}

\section{Activation of proteinases on storage}

Crude extracts of $24 \mathrm{~h}$ mycelial pellets were prepared as described in Methods, stored at different temperatures and then assayed for proteinase activity. Increases in total proteinase activity occurred at all three temperatures (Fig. 1) but were most rapid and extensive at the highest temperature where a sixfold increase in activity was reached after $2 \mathrm{~d}$ storage. With storage at $-12{ }^{\circ} \mathrm{C}$, slow increases in activity have been observed up to six months. In order to see whether an increase occurred in all proteinase activities during storage, the proteinases were separated by PAGE in which a proteinase substrate, azocasein, was incorporated into the gels. Using this separation procedure, three proteinase activities, designated I, II and III, could be routinely detected in the gels and occasionally a fourth band was observed. In order to check that the peaks were not artefacts formed by combination between azocasein and proteinases during electrophoresis, gels were also run without azocasein and then soaked in azocasein solutions after electrophoresis. The same band pattern was still observed. In order to characterize the three proteinase bands further, their sensitivities to inhibitors were tested. When the freshly prepared crude extracts were incubated with either $1 \mathrm{mM}-\mathrm{PMSF}$ or $1 \mathrm{mM}-\mathrm{HgCl}_{2}$ for $10 \mathrm{~min}$ prior to application on the gel, it was found that peak II was partially inhibited by PMSF and completely inhibited by $\mathrm{HgCl}_{2}$, whereas peak III was completely inhibited by PMSF but was insensitive to $1 \mathrm{mM}-\mathrm{HgCl}_{2}$. Higher concentrations of PMSF did not effect more complete inhibition of peak II. Peak I activity was very low in the freshly prepared extracts and thus its sensitivity at that stage could not be reliably tested. However, after $3 \mathrm{~d}$ storage at $20^{\circ} \mathrm{C}$, when its activity was considerably increased, it was found to be completely inhibited by $1 \mathrm{mM}$-PMSF or $1 \mathrm{mM}-\mathrm{HgCl}_{2}$.

The electrophoretic pattern obtained with extracts stored at $4{ }^{\circ} \mathrm{C}$ is shown in Fig. 2. There was a progressive increase in peak I activity, a slight increase in peak II activity and a marked diminution of peak III activity. Similar changes occurred when the extracts were stored at $20^{\circ} \mathrm{C}$ and at $-12{ }^{\circ} \mathrm{C}$, but the rates were faster at $20^{\circ} \mathrm{C}$ and very much slower at $-12^{\circ} \mathrm{C}$. The precise electrophoretic pattern observed with the initial extract was slightly variable: on some occasions peak I was just detectable and others not, and the size of peak III varied slightly. These variations might depend on how rapidly the mycelia were harvested and the crude extract prepared and separated by electrophoresis. Thus, during storage there was a change in the relative proportion of the three proteinases at a time when an increase in the total proteinase activity was also occurring. It is convenient to assay for total proteinase activity using hide powder azure as the substrate because of its high sensitivity, whereas azocasein, because of its greater solubility, is more easily incorporated into gels.

\section{Detection of proteinase inhibitors}

The increases in proteinase activities during storage could be due to zymogen activation or removal of inhibitors. In view of the findings in other organisms (Wolf \& Holzer, 1980) the latter possibility was investigated. In $S$. cerevisiae two heat stable inhibitors of proteinases A and B 


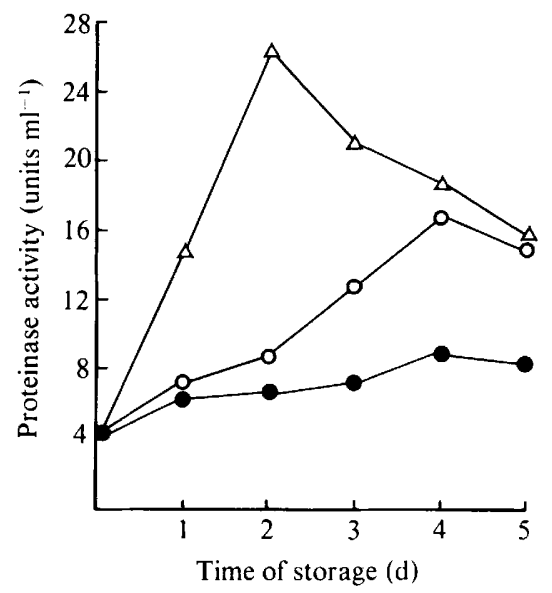

Fig. 1. Activation of proteinases from $A$. nidulans during storage. Crude mycelial extracts were prepared from $24 \mathrm{~h}$ cultures and then stored at $20^{\circ} \mathrm{C}(\triangle), 4^{\circ} \mathrm{C}(\mathrm{O})$ and $-12^{\circ} \mathrm{C}(O)$. Proteinase activity was measured at $\mathrm{pH} 6.5$ as described in Methods.

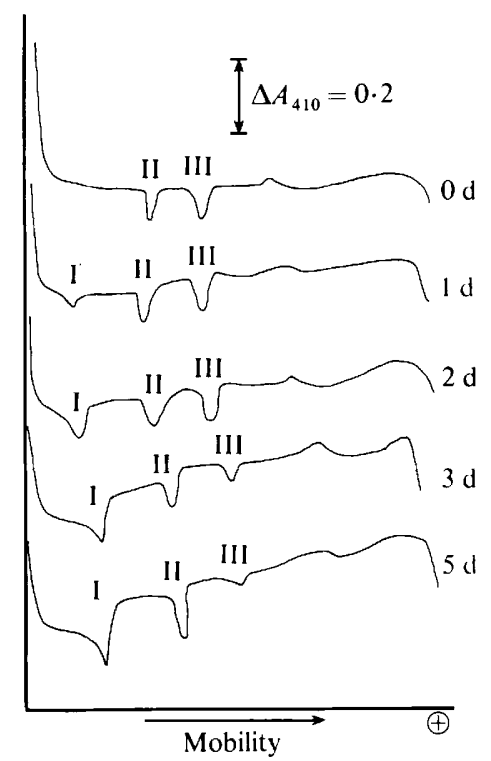

Fig. 2. Electrophoretic separation of proteinase activities from $A$. nidulans after storage at $4{ }^{\circ} \mathrm{C}$ for various times. Crude mycelial extracts containing 0.4-2.0 units of proteinase were separated by PAGE as described in Methods.

have been found (Wolf \& Holzer, 1980). Freshly prepared crude extracts from $24 \mathrm{~h}$ mycelia were placed in a boiling water bath for $10 \mathrm{~min}$. The extracts were cooled and the soluble material was removed by centrifugation at $27000 \mathrm{~g}$ for $10 \mathrm{~min}$. This supernatant (fraction In) was tested for inhibitory activity by mixing it with fresh mycelial extract in various proportions and then assaying for proteinase activity. There was an approximately linear relationship between the amount of fraction In and the degree of inhibition (Fig. 3). Since fraction In contained protein it was possible that the reduction in proteinase activity could have been due to competition between this fraction and the hide powder azure as substrate. However, the control, in which an equivalent amount of bovine serum albumin was added, showed this not to be the case. Fraction In retained its inhibitory activity on dialysis. 


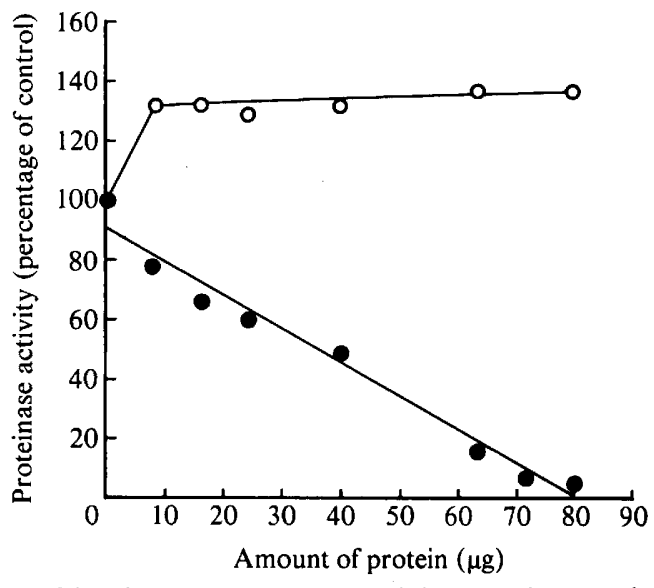

Fig. 3. Effect of addition of fraction In to extracts containing proteinase activity. Various amounts of fraction In (O) were mixed with crude mycelial extracts containing 0.4 units of proteinase activity. Comparable amounts of bovine serum albumin protein $(O)$ were used for controls. Proteinase activity was assayed as described in Methods.

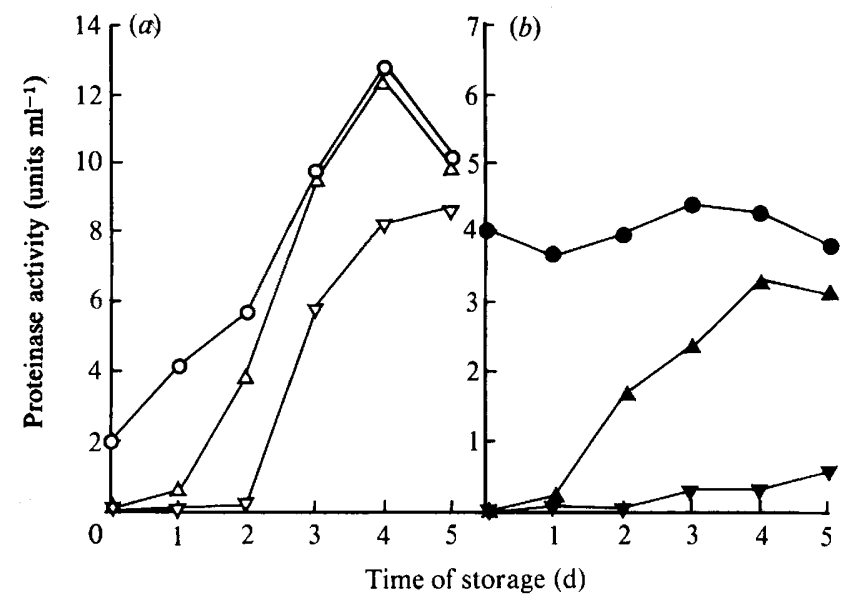

Fig. 4. Effect of storage of crude mycelial extracts on their proteinase inhibitory activity. (a) $\bigcirc$, Crude extracts stored at $4{ }^{\circ} \mathrm{C}$ and assayed daily; $\nabla$, crude extracts stored at $4{ }^{\circ} \mathrm{C}$ for up to $5 \mathrm{~d}$ and mixed with equal volumes of fraction $\mathrm{In}_{0} ; \triangle$, crude extracts stored at $4^{\circ} \mathrm{C}$ for up to $5 \mathrm{~d}$ and mixed with equal volumes of fractions $\mathrm{In}_{0}-\mathrm{In}_{5}$. (b) , Peak I stored at $4{ }^{\circ} \mathrm{C}$ for up to $5 \mathrm{~d} ; 7$, peak I stored up to $5 \mathrm{~d}$ and mixed with an equal volume of fraction $\operatorname{In}_{0} ; \Delta$, peak I stored up to $5 \mathrm{~d}$ and mixed with fractions $\operatorname{In}_{0}-$ $\mathrm{In}_{5}$. For the definition of fractions $\mathrm{In}_{0}-\mathrm{In}_{5}$ and peak $I$ see Results.

The increase in proteinase activity on storing mycelial extracts could therefore be due to either the removal or digestion of the inhibitory activity. In order to test this, crude mycelial extracts, which had been stored at $4^{\circ} \mathrm{C}$ for various periods, were used to prepare In fractions (referred to as $\mathrm{In}_{0}, \mathrm{In}_{1}, \mathrm{In}_{2}$ etc., depending on the number of days storage). These fractions were tested for inhibitory activity against both fresh and stored crude extracts (Fig. $4 a$ ) and against partially purified peak I proteinase (Fig. $4 b$ ). The proteinase activity of the crude extract increased during storage but the addition of fraction $\mathrm{In}_{0}$ caused a reduction of 4-6 units in the proteinase activity of crude extracts which had been prepared after $1-4 \mathrm{~d}$ storage at $4{ }^{\circ} \mathrm{C}$ (Fig. $4 a$ ). On day 0 , there was probably an excess of inhibitor when compared with proteinase. By contrast, when fraction In was prepared from crude extract which had been stored for up to $5 \mathrm{~d}$ 


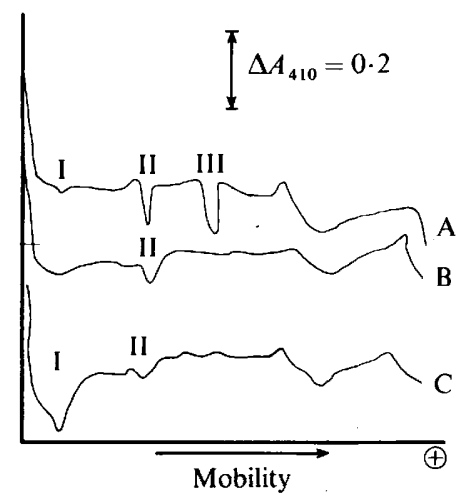

Fig. 5. Effect of $1 \mathrm{mM}-\mathrm{PMSF}$, followed by storage for $2 \mathrm{~d}$, on the proteinase activity of crude mycelial extracts. A, Electrophoretic separation of a crude extract. B, Electrophoretic separation of a crude extract after incubation with $1 \mathrm{mM}-\mathrm{PMSF}$ followed by dialysis overnight. C, Electrophoretic separation of a crude extract after incubation with $1 \mathrm{mM}$-PMSF, dialysis overnight and storage at $4{ }^{\circ} \mathrm{C}$ for $2 \mathrm{~d}$. The total proteinase activities of $A, B$ and $C$ were in the ratio $1 \cdot 0: 0 \cdot 09: 3 \cdot 4$.

$\left(\mathrm{In}_{0}-\mathrm{In}_{5}\right)$ they showed a progressive decrease in inhibitory activity. The inhibitory factor was thus stable in fraction In but not in crude mycelial extracts.

These results were confirmed when similar experiments were carried out using partially purified peak I (Fig. $4 b$ ). In these experiments, since the proteinase activity was nearly constant during storage, it was more easily seen that the inhibitory factor was stable in fraction In but was lost when crude extracts were stored. When experiments were performed in which the crude extract was stored at $20^{\circ} \mathrm{C}$ and at $-12^{\circ} \mathrm{C}$ and then used to prepare fraction In, similar results were obtained to those in which storage was at $4^{\circ} \mathrm{C}$. However, during storage at $20^{\circ} \mathrm{C}$, inhibitory activity was lost more rapidly from crude extracts, whereas at $-12^{\circ} \mathrm{C}$ inhibitory activity was lost very slowly.

We also showed that inhibitory factor(s) in fraction In were able to inhibit not only proteinase I but also proteinase II and III. This was done by separating proteinase I, II and III by electrophoresis, slicing the gels and then assaying the slices in the presence of fraction $\mathrm{In}_{0}$.

\section{Possible interconversion of proteinases}

During the storage of mycelial extracts there was an increase in the ratio of activities of peak I to peak III. It is possible that this might be due to interconversion of the proteinases. Cohen (1973) suggested that such interconversions may occur during the activation process. An experiment was performed to test this possibility. A freshly prepared crude extract was incubated with $1 \mathrm{mM}-\mathrm{PMSF}$ to inhibit peak III activity. The extract was then dialysed to remove PMSF and stored for $2 \mathrm{~d}$. Dialysis may not be essential since PMSF has a half-life of about $110 \mathrm{~min}$ at near-neutral pH (James, 1978). After $2 \mathrm{~d}$ the total proteinase activity was over $300 \%$ of the original activity and the gel electrophoresis patterns obtained were as shown in Fig. 5. It can be seen that peak III activity was completely inhibited by PMSF and yet this did not prevent the appearance of peak I activity after storage. It is unlikely that the ester formed between peak III enzyme and PMSF was unstable (cf. chymotrypsin, Gold, 1965) and thus the enzyme molecules originally inhibited by PMSF were unlikely to become reactivated under these conditions. It is therefore improbable that peak I was derived from peak III. Peak I, which was activated after $2 \mathrm{~d}$ storage, was completely inhibited by a further exposure to PMSF.

The incubation of crude mycelial extracts with PMSF or $\mathrm{HgCl}_{2}$ prior to electrophoresis could change the mobility of the enzymes which might confuse their identification. This potential problem has been eliminated by carrying out electrophoretic separations, slicing the gels and then incubating the slices in the presence of inhibitors. The proteinase bands appeared in the same positions and exhibited the same sensitivities to inhibitors. 


\section{DISCUSSION}

The intracellular proteinases from $A$. nidulans have a number of features in common with the yeast proteinase system. In both cases activation of the proteinases occurred on storage and in both systems there are physiological inhibitors which combine with the proteinases. In $A$. nidulans the inhibitory activity was heat stable and the fraction containing this activity (fraction In), was stable when stored at $-12^{\circ} \mathrm{C}$. However, the inhibitory activity was lost when crude mycelial extracts were stored. The nature of the inhibitory factor(s) is not yet clear although it is probably a protein since it is non-dialysable and the inhibitory extract contains principally protein; inhibition by some other high molecular weight substance, however, cannot yet be ruled out. As with the yeast proteinase system the inhibitor(s) was probably digested by the proteinase during storage. Further fractionation of fraction In is required to ascertain whether there are separate inhibitors combining with each proteinase. In yeast the proteinases are located in a vacuole whereas the inhibitors are present in the cytosol (Wolf \& Holzer, 1980) and thus interaction between the two in vivo is controlled. We have found the proteinase activities to be almost entirely present in the supernatant after centrifugation of crude extracts at $100000 \mathrm{~g}$ for $60 \mathrm{~min}$ (unpublished results). Vacuoles have been observed microscopically in Aspergillus niger (Smith et al., 1977) although they have not yet been isolated from this genus. It is thus possible that any vacuoles present may have been disrupted in the homogenization step.

We have been consistently able to detect three different proteinase bands by PAGE. These have been obtained from $24 \mathrm{~h}$ mycelia grown with nitrate as the sole source of nitrogen. Cohen (1973) has detected up to five different proteinase bands from $40-48 \mathrm{~h}$ cultures grown in static culture using skimmed milk as the source of nitrogen. By comparison of the electrophoretic mobilities, the sensitivities to inhibitors and the stabilities on storage of the proteinases, it appears that proteinases I, II and III correspond to $\beta, \gamma$ and $\delta$ in Cohen's nomenclature. It is possible that peak II may contain more than a single proteinase since this could account for its incomplete inhibition by PMSF. Some change in peak II appears to occur on storage since in freshly prepared extracts it is partly inhibited by PMSF, but after storage for 3-5 $\mathrm{d}$ it is completely inhibited by PMSF. From our results it seems highly improbable that peak III is transformed to peak I on storage. However, the precise relationship of peaks I, II and III to one another and the nature and multiplicity of inhibitors will only be understood after further separation and characterization has been carried out.

\section{REFERENCES}

ANSARI, H. \& Stevens, L. (1981). Detection and separation of intracellular proteinases from Aspergillus nidulans. Society for General Microbiology Quarterly 8, 277.

COHEN, B. L. (1973). The neutral and alkaline proteases of Aspergillus nidulans. Journal of General Microbiology 77, 521-528.

Fischer, E.-P. \& Thomson, K. S. (1979). Serine proteinases and their inhibitors in Phycomyces blakesleeanus. Journal of Biological Chemistry 254, 50-56.

GolD, A. M. (1965). Sulphonyl fluorides as inhibitors of esterases. Biochemistry 4, 897-901.

JAMES, G. T. (1978). Inactivation of the protease inhibitor phenylmethylsulphonyl fluoride in buffers. Analytical Biochemistry 86, 574-579.

MEUSSDOERFFer, F., TORTORA, P. \& Holzer, H. (1980). Purification and properties of proteinase A from yeast. Journal of Biological Chemistry 255, 12087-12093.

Sedmak, J. J. \& Grossberg, S. E. (1977), A rapid sensitive and versatile assay for protein using
Coomassie brilliant blue G250. Analytical Biochemistry 79, 544-552.

Smith, J. E., Anderson, J. G., Deans, S. G. \& Davis, B. (1977). Asexual development in Aspergillus. In Genetics and Physiology of Aspergillus, pp. 23-58. Edited by J. E. Smith \& J. A. Pateman. London: Academic Press.

Stevens, L., McKinnon, I. M. \& Winther, M. (1976). Polyamine and ornithine metabolism during the germination of conidia of Aspergillus nidulans. Biochemical Journal 158, 235-241.

Stevens, L., Hulea, S. A., Duncan, D., Vasu, S. \& BRAD, I. (1981). Neutral proteinases from Aspergillus niger. Revue roumaine de biochimie 18, 63-66.

Wolf, D. H. \& Holzer, H. (1980). Proteolysis in yeast. In Microorganisms and Nitrogen Sources, pp. 431-458. Edited by J. W. Payne. London: Wiley.

Yu, P. H., SiePen, D., Kula, M. R. \& Tsai, H. (1974). On the stoichiometry and reversibility of interaction between Neurospora protease I and its inhibitor. FEBS Letters 42, 227-230. 